\title{
THE EFFECT OF KAOLIN AND SILICA VARIATION ON THE PROPERTIES OF PORCELAIN INSULATORS
}

\author{
H. E. Mgbemere ${ }^{1,}{ }^{*}$, I. P. Onyeayana ${ }^{2}$ and A. B. Okoubulu ${ }^{3}$

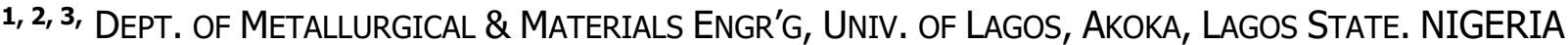 \\ E-mail addresses: ${ }^{1}$ hmgbemere@unilag.edu.ng, ${ }^{2}$ phi5concept@gmail.com, ${ }^{3}$ okoubulua@gmail.com
}

\begin{abstract}
$\mathrm{Clay}, \mathrm{Al}_{2} \mathrm{O}_{3}$, feldspar and silica have been used to produce shackle-type porcelain insulators using slip casting method. The amounts of silica and kaolin were varied from 10 to 30 wt. \% while keeping the amounts of other constituents constant. The samples were bisque fired at $900^{\circ} \mathrm{C}$, sintered at $1200^{\circ} \mathrm{C}$ for 1 hour glazed using borax fritz. The results showed that as the amount of kaolin decreased, apparent porosity and water absorption increased from 9-19\% and 7-12\% respectively. The bulk density and linear shrinkage decreased from $1.94-1.12 \mathrm{~g} / \mathrm{cm}^{3}$ and from 12.5 $\%-7 \%$ respectively. Breakdown voltages ranging from $23 \mathrm{kV}$ to $35 \mathrm{kV}$ were obtained while the highest insulation resistance value of $50 \mathrm{G} \Omega$ was for the sample with $55 \%$ clay, $15 \%$ silica and 25 $\%$ feldspar and $5 \% \mathrm{Al}_{2} \mathrm{O}_{3}$. The results indicate that moderate variations in kaolin and silica content can be used to produce porcelain insulators for commercial applications.
\end{abstract}

Keywords: Electrical porcelain, Shackle insulator, Kaolin, Feldspar, Processing.

\section{INTRODUCTION}

Electrical insulators are usually produced from kaolin, feldspar and quartz referred to as triaxial porcelain but recently other materials like polymer, composites and glass have been used [1]. They are used to prevent the flow of electrical current and so find applications as high voltage insulators in the transmission of electricity [2]. Despite the discovery of other alternatives, electrical porcelain continues to be used because they exhibit high stability in their electrical, thermal and electro-mechanical properties [3]. Depending on their areas of application, different types of porcelain insulators exist but the three major types are pin insulator, suspension insulator and strain insulator [4].

The raw materials needed for the production of electrical insulators are in abundance in the country yet most of the high voltage insulators used are imported. Literatures exist on body compositions and the processing conditions to produce porcelain insulators by both local and foreign researchers. The properties of electrical porcelain produced using clays from Iva Valley, Nawfija and Ekwulobia have been investigated[5]. Bisque firing at $900^{\circ} \mathrm{C}$ and glazing at $1250^{\circ} \mathrm{C}$ were carried out after air-drying. The composition that gave the best properties from Ekwulobia and Iva Valley clays has composition of $60 \%$ clay, $25 \%$ feldspar and $15 \%$ silica. Ezenwabude \& Madueme [6] evaluated the mixture of raw materials for low voltage insulators by varying the compositions of clay, fireclay, feldspar and quartz through slip casting [6]. The specimen with composition of $50 \%$ clay, 20\% feldspar and 30\% quartz was found to possess high quality properties; water of absorption $(14.44 \%)$, and porosity $(25.23 \%)$, bulk density

$\left(1.75 \mathrm{~g} / \mathrm{cm}^{3}\right)$, insulation break down voltage of $45 \mathrm{~V}$. The use of Ukpor Clay to produce porcelain was also studied [7]. A break down voltage of $26 \mathrm{kV} / \mathrm{mm}$, low water absorption and dielectric constant between 9.0 and 10.9 were obtained [8]. Analysis of electrical porcelain from kaolin found in Ikere-Ekiti, Ile-Ife and Iwo using slip casting showed that Ile-Ife and Iwo kaolin did not withstand the bisque firing temperature of $900{ }^{\circ} \mathrm{C}$. Examination of the effects of sintering on the properties of triaxial electrical porcelain produced from Ugandan ceramics indicates that Sintering at 
$1250{ }^{\circ} \mathrm{C}$ did not result in any significant improvement in the strength of the porcelain [9]. Flashover voltages of $20.3 \mathrm{kV}$ (dry) and 9.3kV (wet) respectively, transverse strength of $12.5 \mathrm{kN}$ and bulk density of $2.27 \mathrm{~g} / \mathrm{cm}^{3}$ were reported. Okolo et al., studied the dielectric strength of electrical porcelain insulators using snail shell and by varying the quantities of silica and feldspar required to form a mouldable plastic body with each clay sample [5]. Nwachukwu and Lawal [10] investigated the structure and properties of ceramic raw materials in Tanzania for electrical insulation application. Increasing the kaolin beyond 48 wt. $\%$ and reducing quartz content below $6 \mathrm{wt} . \%$ led to the reduction of electrical insulation and bending strength [10]. The mix with constituent's percentage composition of $48 \mathrm{wt} . \%$ kaolin, $46 \mathrm{wt} . \%$ fields par and $6 \mathrm{wt} . \%$ quartz possesses the highest strength of 53.525MPa.

The objective of this study is to first of all produce porcelain containing only kaolin, feldspar and silica to serve as a guide and in subsequent compositions, to introduce uniform amounts of $\mathrm{Al}_{2} \mathrm{O}_{3}$, ball clay and feldspar while varying the amounts of kaolin and silica. This is done with a view to understanding how variation of these constituents will affect the properties of porcelain insulator.

\section{MATERIALS AND METHODS}

\subsection{Sample Preparation}

The raw materials used for this study are ball clay, kaolin, feldspar, alumina and silica. They were crushed using a jaw crusher and later ground to powders. Ball milling of the powders were later done to further reduce the size of the powders. Composition 1 is purely triaxial porcelain which serves as a form of control for the other compositions. The other electrical porcelain compositions (compositions 2-6) were formulated by varying the amounts of kaolin and silica present while leaving all the other constituents constant. The details of the body formulations are shown in Table 1.
The samples were mixed in the correct proportions and then a slip casting process was initiated. As the amount of $\mathrm{Al}_{2} \mathrm{O}_{3}$ present in the formulation increases, it becomes more difficult to prepare the slip. Sodium silicate was used to aid the formation of a slip. Moulds made from calcium sulphate were prepared and the slip was poured into them. The casts were then allowed to solidify in the mould. They were put in the oven operating at $200^{\circ} \mathrm{C}$ to ensure that all the moisture present was removed. To ensure that the handling of the samples was easy, the samples were bisque fired at $900^{\circ} \mathrm{C}$ in a furnace heated at $5^{\circ} \mathrm{C} / \mathrm{min}$ for 1 hour. The samples were sintered in a gas fired furnace operating at $1300^{\circ} \mathrm{C}$ for 2 hours. Figure 1 (left) shows the images of the bisque fired shackle insulators while the picture on the right shows the glazed insulators.

\subsection{Sample Characterisation}

In order to verify that the raw materials to be used are actually what they should be, chemical analysis using X-ray Fluorescence (Venarum Mines Laboratory Apapa, Lagos) was used to analyse them. The density of the samples was determined using the Archimedes method by suspending them in water using a beaker placed on a weighing balance. The apparent porosity and water absorption capacity of the sintered samples were measured following the ASTM C20-80a standard. The samples were placed in an oven operating at $105^{\circ} \mathrm{C}$ for 12 hours and later weighed, transferred to a vessel containing boiling water for 1 hour. The samples were then removed from the boiling water, dried and re-weighed. The electric resistance of the samples were measured with a multimeter (Fluke-27 Multimeter). The high resistance values of the samples meant that the conductance mode was used to obtain the insulation resistance. The dielectric strength was determined using a Hipotronics tester (Haefely Hipotronics 100HVT-A 100 kV 50mA AC Hipot tester).

Table 1: Table showing the amount of the raw powders used in preparing the electrical porcelain

\begin{tabular}{rccccc}
\hline Composition & Kaolin (wt.\%) & Ball clay (wt. \%) & $\mathrm{SiO}_{2}$ (wt. \%) & Feldspar (wt.\%) & $\mathrm{Al}_{2} \mathrm{O}_{3}$ (wt. \%) \\
\hline 1 & 50 & 0 & 25 & 25 & 0 \\
2 & 30 & 30 & 10 & 25 & 5 \\
3 & 25 & 30 & 15 & 25 & 5 \\
4 & 20 & 30 & 20 & 25 & 5 \\
5 & 15 & 30 & 25 & 25 & 5 \\
6 & 10 & 30 & 30 & 25 & 5 \\
\hline \hline
\end{tabular}


The voltage was set at $100 \mathrm{kV}$ and the control was gradually increased until a cracking sound which represents the breakdown voltage is heard.

Test pieces for compression test were shaped to a standard cross sectional area of approximately 633 $\mathrm{mm}^{2}$. They were placed on a compression testing machine (INSTRON 3369 Compression tester) and load was applied axially at a uniform rate until failure occurs. The compressive strength was calculated using the relation: maximum load over cross sectional area. The microstructures of the samples were examined with a scanning electron microscope (VEGA3 TESCAN SEM attached with OXFORD Instrument energy dispersive spectroscopy (EDS) analyser). To ensure that there was electrical contact, the samples were sputtered with gold. The Samples were placed in a sample chamber, vacuum was created and the images were acquired using secondary electron imaging mode.

\section{RESULTS AND DISCUSSIONS}

\subsection{Chemical Composition}

The result of the chemical analysis on the raw materials using X-ray Fluorescence is shown in Table 1. It is observed that in most of the samples, the major constituents are $\mathrm{SiO}_{2}$ and $\mathrm{Al}_{2} \mathrm{O}_{3}$. The kaolin, ball clay and Feldspar contain 51.38 wt.\%, 63.59 wt. \% and 69.12 wt. $\%$ of $\mathrm{SiO}_{2}$ and $42.05,23.37$ and 18.2 wt. \% of $\mathrm{Al}_{2} \mathrm{O}_{3}$ respectively. Apart from the major constituents, impurity elements were also observed in all the raw materials. $\mathrm{Fe}_{2} \mathrm{O}_{3}$ is one of the main impurity elements in these raw materials with a content of 1.39 ,
3.02 and 0.69 wt. \% in kaolin, ball clay and silica respectively. $\mathrm{Na}_{2} \mathrm{O}$ and $\mathrm{TiO}_{2}$ are the other impurity compounds found in the raw materials.

Table 2: The chemical composition of the raw materials used in the production of the electrical

\begin{tabular}{cccccc}
\multicolumn{7}{c}{ porcelain } \\
\hline $\begin{array}{l}\text { Composition } \\
\text { (wt. \%) }\end{array}$ & Kaolin & $\begin{array}{l}\text { Ball } \\
\text { Clay }\end{array}$ & Feldspar & Silica & Alumina \\
\hline $\mathrm{SiO}_{2}$ & 51.38 & 63.59 & 69.12 & 93.49 & 0.13 \\
$\mathrm{Al}_{2} \mathrm{O}_{3}$ & 42.05 & 23.37 & 18.2 & 0.014 & 97.35 \\
$\mathrm{Fe}_{2} \mathrm{O}_{3}$ & 1.39 & 3.02 & 0.074 & 0.69 & 0.02 \\
$\mathrm{MgO}$ & 0.02 & - & 0.17 & - & - \\
$\mathrm{CaO}$ & 0.16 & 0.57 & 0.21 & - & - \\
$\mathrm{Na} 2$ & 1.73 & 0.87 & 6.24 & 0.051 & 0.35 \\
$\mathrm{~K}_{2} \mathrm{O}$ & 0.43 & 1.18 & 2.83 & $<0.001$ & $<0.001$ \\
$\mathrm{TiO}_{2}$ & 2.37 & 0.93 & 0.173 & 0.023 & 1.26 \\
$\mathrm{BaO}$ & $<0.001$ & 0.039 & 0.011 & 0.039 & 0.03 \\
$\mathrm{ZnO}$ & 0.005 & $<0.001$ & & $<0.001$ & - \\
$\mathrm{P}_{2} \mathrm{O}_{5}$ & - & - & 0.05 & 0.12 & - \\
$\mathrm{MnO}$ & 0.007 & - & - & 0.07 & - \\
$\mathrm{PbO}$ & - & - & - & 0.032 & - \\
\hline \hline
\end{tabular}

\subsection{Bulk Density}

The graph of bulk density as a function of sample composition for the porcelain insulators is shown in figure 2. The observed trend is that as the silica content in the porcelain insulators increased (i.e. decreasing amount of kaolin), the bulk density values decreased. The obtained density value for the sample with composition 1 is $1.93 \mathrm{~g} / \mathrm{cm}^{3}$.
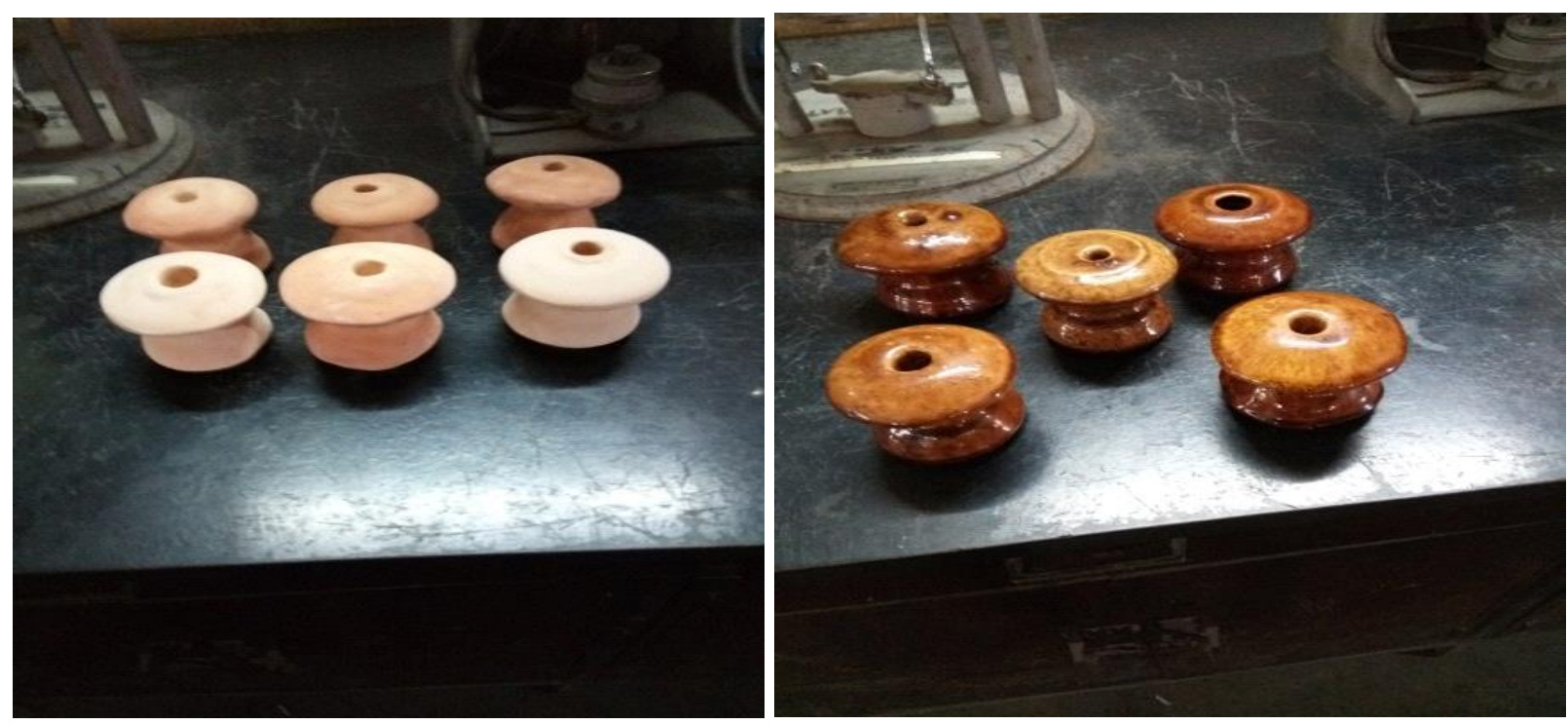

Figure 1: Pictures showing different shackle insulators in their (left) bisque fired state and (right) sintered and glazed state. 
The density values gradually decreased to $1.2 \mathrm{~g} / \mathrm{cm}^{3}$ for sample with composition 5 . The value of the sample with composition 6 is however different increasing to $2.2 \mathrm{~g} / \mathrm{cm}^{3}$. The possible reasons for the significant difference in density could be due to impurity elements which may have favoured sintering at that temperature. The obtained values in this research are within the range of density values reported by Atanda et al, [8] but is lower than that reported by Nwachukwu and Lawal [10]. The difference in values can be traced to compositional differences used to produce the different porcelain.

\subsection{Apparent Porosity and Water Absorption}

The results of the apparent porosity and water absorption tests are shown in fig. 3. For both graphs, it is observed that as the amount of silica increased (i.e. decreasing kaolin content), the porosity and water absorption coefficient values increased. The apparent porosity values increased from $9.12 \%$ for composition 1 to $20 \%$ for composition 6 . The values here are relatively higher than those reported in the literature $[3,11]$ but lower than that reported by Ezenwabude [6]. The percentage water absorption coefficient for composition 1 is $6 \%$ and it steadily increased to $11.8 \%$ for composition 6 .

\subsection{Compressive Modulus}

The plot of compressive stress against compressive strain for the porcelain insulators with different compositions is shown in Figure 4. The sample with composition 1 has the lowest stress values. The modulus which is the ratio of stress against strain is calculated to be $13.2 \pm 0.27 \mathrm{MPa}$. The modulus increases in compositions 2 and 3 with values of $76.79 \pm 0.62 \mathrm{MPa}$ and $140.29 \pm 5.14 \mathrm{MPa}$ respectively. The modulus values gradually decreased from composition 4 to 6 and were $65.6 \pm 0.58 \mathrm{MPa}$, $81.85 \pm 0.64 \mathrm{MPa}$ and $37.55 \pm 0.29 \mathrm{MPa}$ respectively. Compared to the results of compressive strength reported by Atanda et al, [12] (2.55 - $2.69 \mathrm{MPa})$, relatively high values were obtained in this work. The reason for this could be compositional differences and method of sample preparation.

\subsection{Electrical Measurements}

The results of the electrical measurements carried out on the porcelain insulator samples are shown in Table 3. Withstand voltage is used to estimate the amount of voltage that the insulator can resist when voltage is applied in still air at $25{ }^{\circ} \mathrm{C}$ for three minutes. The highest withstand voltage of $15 \mathrm{kV}$ was obtained for composition 1 . The value gradually reduces to 11 and $8 \mathrm{kV}$ for compositions 2 and 3 respectively before stabilizing at $10 \mathrm{kV}$ for compositions 4 to 6 . The inception voltage measures the lowest voltage where partial discharge or localised dielectric breakdown occurs in a small portion of the porcelain insulator when high voltage stress is applied. The highest inception voltage of $30 \mathrm{kV}$ was recorded with composition 1 and again sharply decreases to $15 \mathrm{kV}$ for compositions 2 and 3 . This difference in values may be related to the differences in sample composition and physical properties of the insulator. The value increases to $19 \mathrm{kV}$ for composition 4 and then decreases to 16 and $14 \mathrm{kV}$ for compositions 5 and 6 respectively.

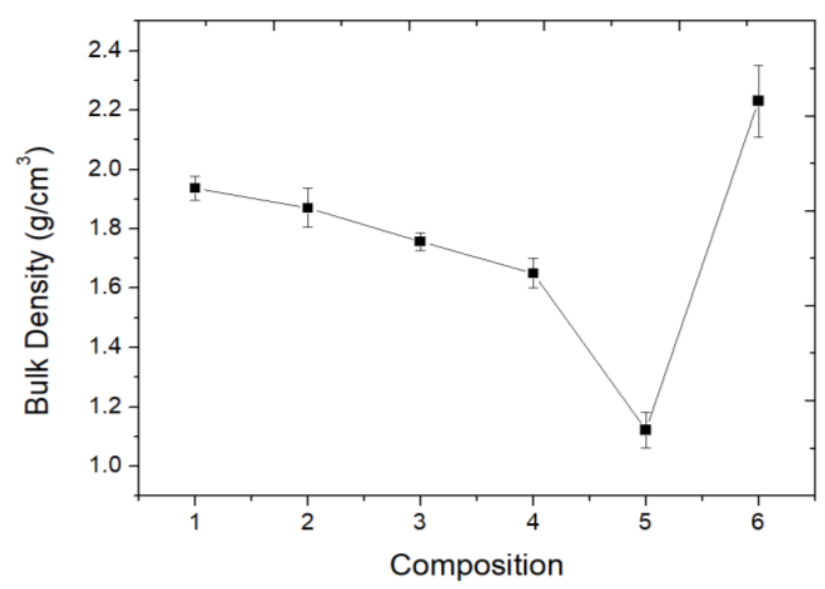

Figure 2: The bulk density values of the electrical porcelain insulators. The measurements were made at room temperature using the Archimedes method of density determination.

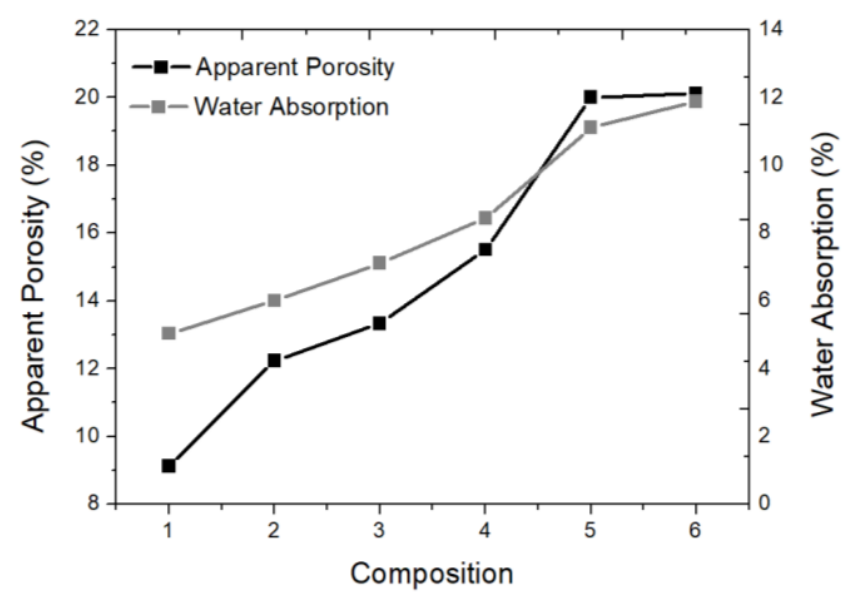

Figure 3: Graphs showing the apparent porosity values and water absorption in percentage as a function of composition.

Vol. 38, No. 2, July 2019 


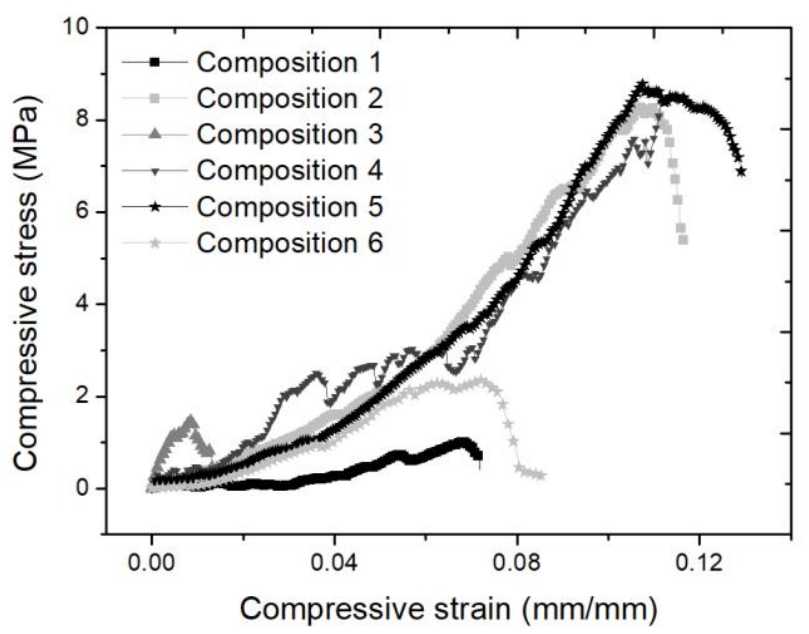

Figure 4: Graph showing the compressive stress as a function of compressive strain for the porcelain insulators measured at room temperature.

The breakdown voltage is a very important parameter for insulators because it indicates the minimum voltage that will make a part of the porcelain insulator to be electrically conductive. Composition 1 also has the highest breakdown voltage of $35 \mathrm{kV}$ while compositions 2 and 3 have $30 \mathrm{kV}$. The obtained values for these two compositions are high compared to the result $(26 \mathrm{kV} / \mathrm{mm})$ reported by Ajakor et al, [7]. The breakdown voltage values decrease for compositions 4 and 5 to $23 \mathrm{kV}$ while composition 6 has $34 \mathrm{kV}$. The values of the breakdown voltage for the samples generally decreased increasing silica content. There is an argument as to whether the voltage should decrease or not. While Okolo et al, reported that increasing the silica content of their mixture resulted in an increased dielectric strength of the porcelain [5], Sedghi et al, reported that when the silica content decreased, the bend strength increased while the dielectric strength of the porcelain also increased to an extent. The later is in-line with our result where the breakdown voltage decreased with increasing silica content [13].

The leakage current for all the samples are $0.4 \mathrm{~A}$ possibly because the sensitivity of the measuring device is too low to detect very small differences in current. Insulation resistance which is a measure of the opposition to the flow of current through the porcelain insulator is between $2.5 \mathrm{G} \Omega$ and $50 \mathrm{G} \Omega$ for all the samples. Composition 5 has the lowest value of $2.5 \mathrm{G} \Omega$ while composition 3 has the highest resistance value of $50 \mathrm{G} \Omega$ which is slightly higher than that reported by Moyo \& Park [11]. The reason for the high insulation resistance value for composition 3 could be that appropriate amounts of the constituents were used. This is supported by the relatively dense microstructure (plate 1c) and high compressive modulus obtained for this composition. The insulation resistance values for compositions 2, 5 and 6 are one order of magnitude lower than those for compositions 1,3 and 4.

\subsection{Scanning Electron Microscopy}

The scanning electron micrographs of the porcelain insulator samples showing their morphologies are as shown in plate 1 . Composition 1 is represented with plate $1 a$ and it shows that the grains are relatively small, the sample is dense with very few pores. This is reflected in the density value of $1.93 \mathrm{~g} / \mathrm{cm}^{3}$. Plate $1 \mathrm{~b}$ stands for composition 2 and it can be seen here that the grains are slightly higher with more pores. This also correlates with the slightly lower value of the density. Plate $1 \mathrm{c}$ represents composition 3 which had the best compressive strength result and good electrical insulation properties. The grains are equally small with some pores and a slightly lower bulk density value. Composition 5 is represented using plate $1 \mathrm{e}$.

Table 3: A table showing the results of the electrical measurements carried out on the different porcelain insulators

\begin{tabular}{|c|c|c|c|c|c|}
\hline Composition & $\begin{array}{l}\text { Withstand } \\
\text { Voltage (kV) }\end{array}$ & $\begin{array}{c}\text { Inception } \\
\text { Voltage (kV) }\end{array}$ & $\begin{array}{l}\text { Breakdown } \\
\text { Voltage (kV) }\end{array}$ & $\begin{array}{l}\text { Leakage } \\
\text { Current }(\mathrm{A})\end{array}$ & $\begin{array}{c}\text { Insulation } \\
\text { Resistance }(\mathrm{M} \Omega)\end{array}$ \\
\hline 1 & 15 & 30 & 35 & 0.4 & $30 \times 10^{3}$ \\
\hline 2 & 11 & 15 & 30 & 0.4 & $30 \times 10^{2}$ \\
\hline 3 & 8 & 14.5 & 30 & 0.4 & $50 \times 10^{3}$ \\
\hline 4 & 10 & 19 & 23.5 & 0.4 & $15 \times 10^{3}$ \\
\hline 5 & 10 & 16 & 23 & 0.4 & $25 \times 10^{2}$ \\
\hline 6 & 10 & 14 & 34 & 0.4 & $30 \times 10^{2}$ \\
\hline
\end{tabular}


Very large grains which are not well bonded to each other can be observed in the micrograph. The low density value of $1.2 \mathrm{~g} / \mathrm{cm}^{3}$ obtained for this composition in figure 1 is very much related to the microstructure of the sample. The morphology of composition 6 shows fine grains with very little porosity which can explain why the bulk density is the highest of all.
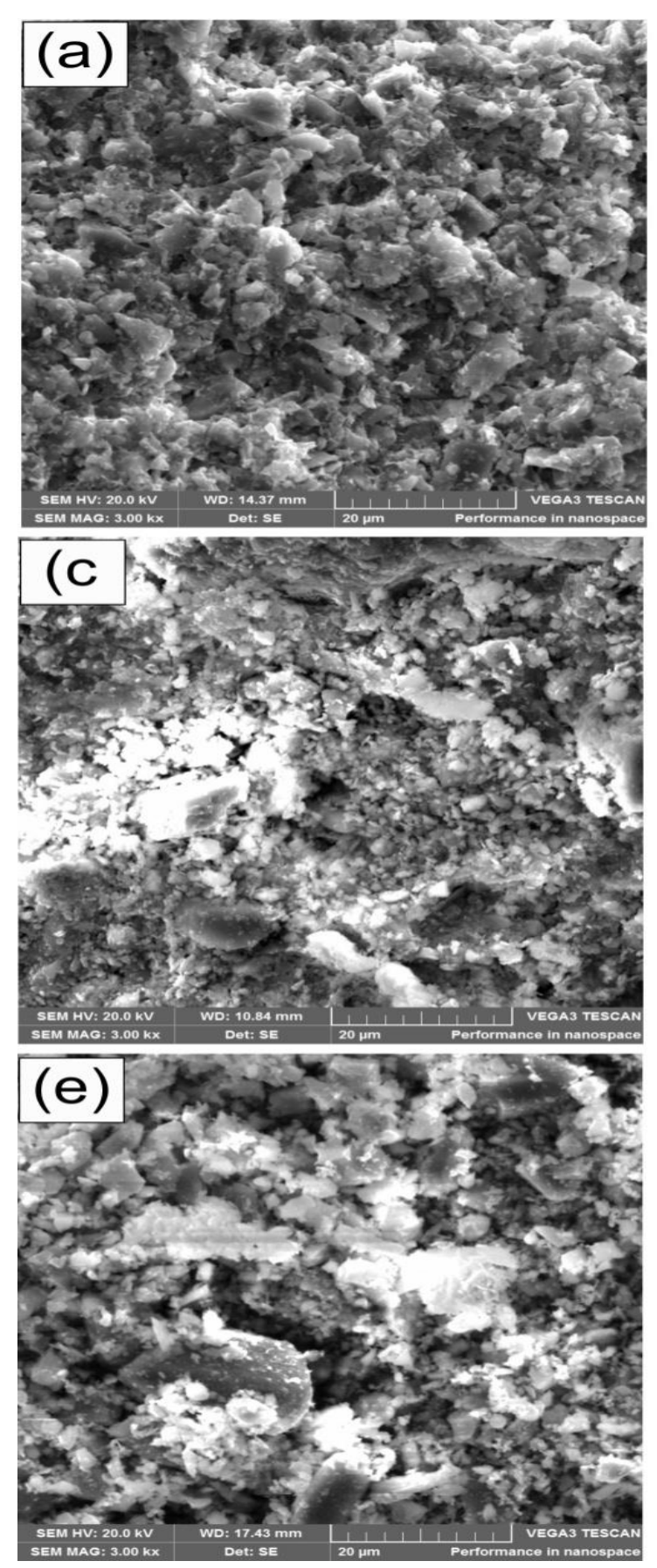

\section{CONCLUSION}

Shackle-type electrical porcelain insulators have been produced in this research from locally available raw materials and the effects of varying the amounts of silica and kaolin have been investigated. The bulk density values are between 1.2 and $2.2 \mathrm{~g} / \mathrm{cm}^{3}$ and as the kaolin content in the porcelain decreases, the density values decreases. The apparent porosity and water absorption coefficient values of the samples increased with decreasing kaolin content from 7-19\% and $5.8-11.8 \%$ respectively.
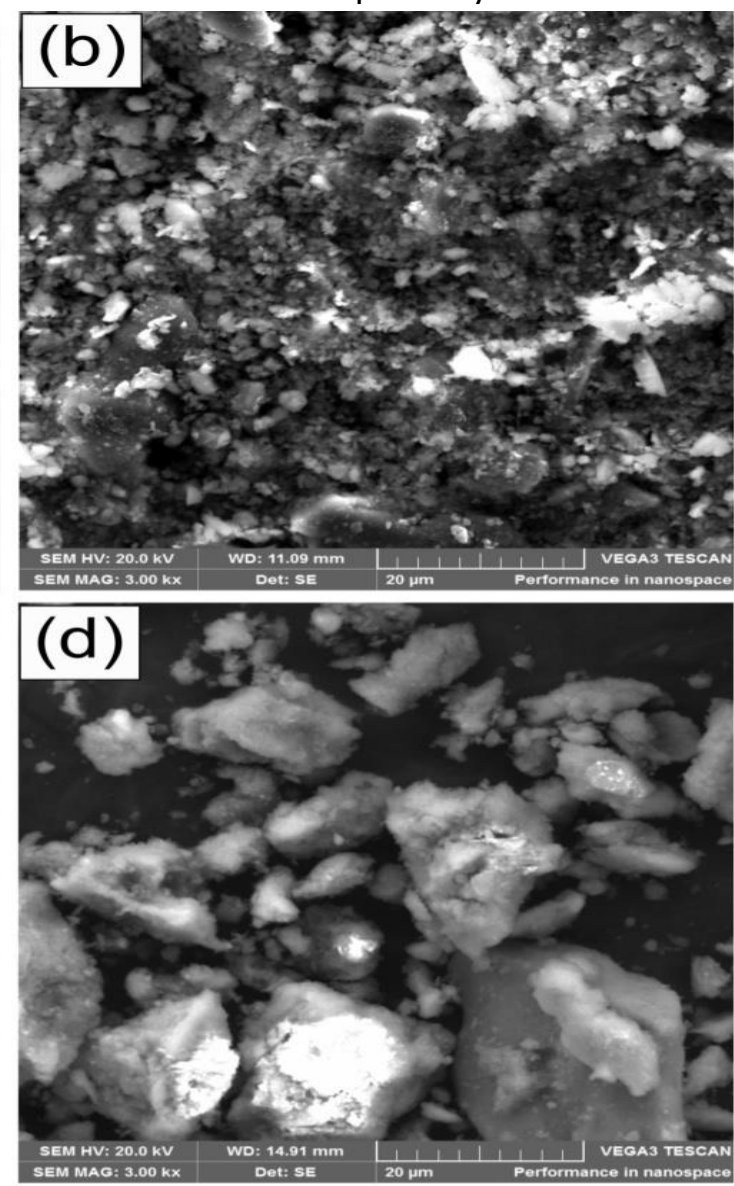

Plate 1: Scanning electron micrographs of the porcelain insulators produced by varying the amounts of kaolin and silica 
The compressive modulus of the porcelain increased with decreasing kaolin content to a certain extent. Composition 3 gave the highest modulus value of 176 MPa while composition 1 gave the lowest value of 13.2 MPa. The electron micrographs show that as the kaolin content decreases with increasing silica content, the porosity in the samples gradually increases leading to slightly lower density values. Increasing the silica content resulted in a decreasing breakdown voltage while the insulation resistance values of the porcelain initially increased before decreasing. This implies that silica content not more than $15 \%$ is required for this formulation to obtain enhanced properties. The results indicate that porcelain insulators can effectively be produced and commercialised using locally available materials.

\section{REFERENCES}

[1] A. P. Mecano, "Introduction to High and Low Voltage Power Supplies," 2011, pp. 88-93.

[2] O. P. Khanna, "Material Science and Metallurgy," Revised and Enlarged edition ed New Delhi: Dhamput RAI Publications (P) Ltd, 2001.

[3] L. U. Anih, "Indigenous Manufacturer and Characterization of Electrical Porcelain Insulator," Nigerian Journal of Technology, vol. 24, pp. 1-7, 2005.

[4] J. P. Holtzhausen, "High Voltage Engineering Practice and Theory," 2015.

[5] C. C. Okolo, O. A. Ezechukwu, C. O. Olisakwe, C. E. Ezendokwelu, and C. Umunna, "Characterization of Electrical Porcelain Insulators from Local Clays," International Journal of Research - Granthaalayah, vol. 3, pp. 26-36, 2015.

[6] Ezenwabude and T. C. Madueme, "Investigated the Evaluation of Mixed Local Materials for Low Voltage Insulators," International Journal of Multi-Disciplinary Sciences and Engineering, vol. 6, p. 37, 2015.
[7] E. M. Ajakor, L. U. Anih, and C. M. Ogwata, "Indigenous Production of Electrical Porcelain from Nigerian Mineral," International Journal of Scientific and Research Publications, vol. 5, pp. 1-3, 2015.

[8] P. O. Atanda, O. O. Oluwole, and T. A. Oladeji, "Electrical Porcelain Production From Selected Kaolin Deposit in South Western Nigeria Using Slip Casting," International Journal of Materials and Chemistry vol. 2, pp. 86-89, 2012.

[9] P. W. Olupot, "Assessment of Ceramic Raw Materials in Uganda for Electrical Porcelain," in Department of Materials Science and Engineering. vol. Licentiate Thesis in Material Science Stockholm: Royal Institute of Technology (KTH) Sweden, 2006.

[10] V. C. Nwachukwu and S. A. Lawal, "Investigating the Production Quality of Electrical Porcelain Insulators from Local Materials," IOP Conf. Series: Materials Science and Engineering, vol. 413, 2018.

[11] M. G. Moyo and E. Park, "Investigated the ceramic raw materials in Tanzania - structure and properties for electrical insulation application," International Journal of Engineering Research \& Technology (IJERT), vol. 4, pp. 3441, 2014.

[12] P. O. Atanda, O. O. Oluwole, and O. T. Ogale, "Adaptation Of Ushafa Clay as a suitable replacement for Bentonite in the Foundry Industry," Journal of Raw Materials Research, Raw Materials Research and Development Council Abuja, vol. 5, pp. 53-60, 2008.

[13] A. Sedghi, N. Riahi-Noori, N. Hamidnezhad, and M. R. Salmani, "Effect of Chemical Composition and Alumina Content on Structure and Properties of Ceramic Insulators," Bull. Mater. Sci., vol. 37, pp. 321-325, 2014. 